\title{
A control strategy of hybrid solar-wind energy generation system
}

\author{
himanshu Sharma, Nitai Pal, Pankaj Kumar, Ashiwani Yadav \\ Department of Electrical Engineering, IIT (ISM) \\ Dhanbad, Jharkhand, India, 826004 \\ e-mail:himanshu26sharma@gmail.com
}

(Received: 17.04.2016, revised: 11.10.2016)

\begin{abstract}
Synchronization in the energy generated by renewable energy sources is one of the significant issue associated with the converter used in the system module. The presented paper concentrates on the design aspect of a PV and wind power input to a DC-DC converter which can be practically useful in hybrid renewable energy power systems. In this regard, the proposed converter can be utilized to obtain a smooth regulated output voltage from the given input renewable energy power sources. The proposed converter can be efficiently work under critical conditions having very few ripple in current waveform of input or output. A major advantage with this type of converter is the simple circuit with respect to the conventional converters in some critical situations. At the end, the result based on the simulation exercise and various experiments, performance of the converter in different situations is presented so that the efficiency of the designed converter arrangement is accepted.
\end{abstract}

Key words: distributed PV/wind power system, double-input DC-DC converter, multivariable controller, voltage regulation

\section{Introduction}

A hybrid system can be defined as an electrical system having one or more energy sources along with at least one source as renewable energy source. Wind energy as well as solar energy using a photovoltaic array are two major environmentally friendly sources of energy [1]. There are mainly two types of hybrid systems, one is grid connected and the other one is in standalone mode $[2,3]$. The hybrid photovoltaic (PV) and wind turbine system (WT) can be mainly applied in the systems like water pumping, domestic as well as street lighting, surface mine lighting, various vehicle applications etc.

The projected hybrid structure comprises of one wind blade, one fluctuating speed wind alternator, an $\mathrm{AC} / \mathrm{DC}$ converter attached to the wind side, a $\mathrm{PV}$ module, a $\mathrm{DC} / \mathrm{DC}$ chopper, a DC/DC converter to get the controlled DC output with a desired voltage level and a DC/AC converter is used to get the controlled output $\mathrm{AC}$ voltage as required by the load as shown in Fig. $1[4,5]$. 


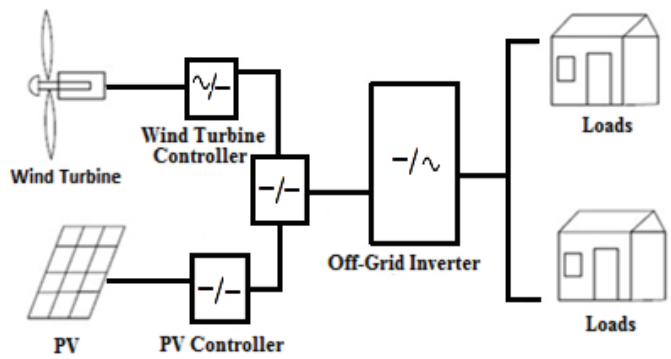

Fig. 1. Hybrid generation system model

A typical DC capacitor is also attached in addition to an applied load to suppress the harmonics. From a common DC line, a parallel connection is provided for two power sources [6].

\section{Operation principle of designed converter}

In this survey, the principle is to synthesize different DC/DC converters to create MIC. Two Cuk converters have been used for the structure of the given converter. The circuit diagram of this converter is given in Fig. 2. It includes two DC input sources $\left(V_{1}, V_{1}\right)$.

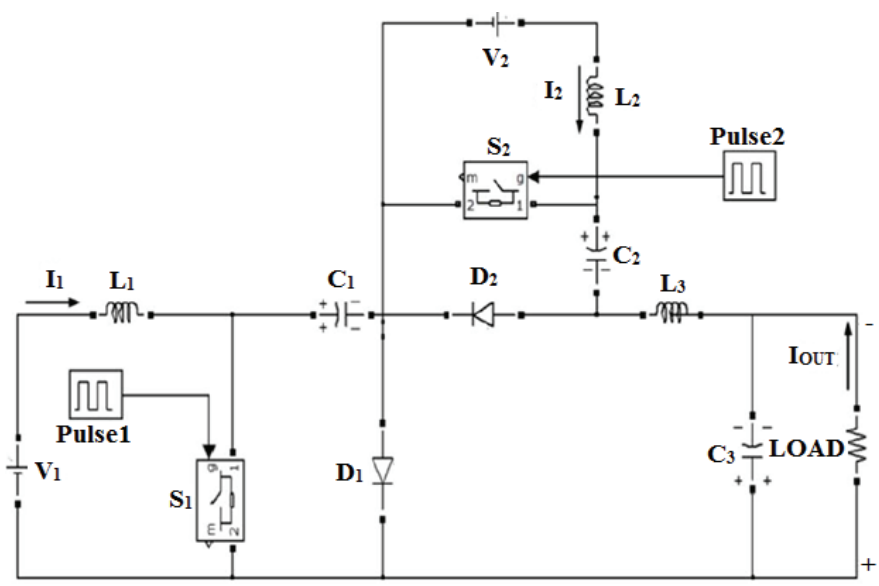

Fig. 2. Designed circuit of proposed converter

The bypass path for the inductors $L_{1}$ and $L_{2}$ currents to flow continuously is provided by power diode $D_{1}$ and $D_{2}$. The projected dual input DC-DC converter can take power from two voltage sources separately or simultaneously, by applying an appropriate control scheme to the pulse generator of the power switches $S_{1}$ and $S_{2}$. On the other hand, based on the control scheme and input sources, the output voltage can be regulated at the reference value [7]. The energy transfer elements are capacitors $C_{1}$ and $C_{2}$. The duty of capacitor $C_{3}$ is to eliminate the ripple of the output voltage like in the conventional converters.

It has four modes of operation, which are categorized with respect to the status of the power switches $\left(S_{1}\right.$ and $\left.S_{2}\right)$ : 
Mode I ( $S_{1}$ ON and $S_{2} \mathrm{ON}$ ): in this mode, the input voltage sources $V_{1}$ (Solar) [8] and $V_{1}$ (Wind) charge the input inductors $L_{1}$ and $L_{2}$ and at the same time, $C_{1}$ and $C_{2}$ discharge and supply energy to the output load [9]. Since, $S_{1}$ and $S_{2}$ are conducting, power diodes $D_{1}$ and $D_{2}$ are reversed biased and should be considered as an open circuit (OC).

Mode II $\left(S_{1} \mathrm{ON}\right.$ and $\left.S_{2} \mathrm{OFF}\right)$ : in this mode, the power diode $D_{1}$ is reversed biased, thus, operates as an open circuit and $D_{2}$ is forward biased and acts as a short circuit (SC). During operation, $V_{1}$ charges the inductor $L_{1}$ and $V_{1}$ charges capacitor $C_{2}$. The inductor $L_{2}$ releases its energy to the capacitor $C_{2}$.

Mode III ( $S_{1} \mathrm{OFF}$ and $\left.S_{2} \mathrm{ON}\right)$ : here, $D_{1}$ is forward biased and conducts, whereas the $D_{2}$ is reversed biased, so it is blocked. In this mode, $V_{1}$ and $L_{1}$ charges the capacitor $C_{1}$. Similarly, inductor $L_{2}$ is charged by voltage produced by $V_{1}$. Capacitor $C_{2}$ is discharged to provide energy to the load.

Mode IV ( $S_{1}$ OFF and $S_{2}$ OFF): the diodes $\left(D_{1}\right.$ and $\left.D_{2}\right)$ are forward biased and taken as a short circuit (SC). Here, the capacitors $C_{1}$ and $C_{2}$ are charged by $V_{1}$ and $V_{1}$, respectively.

Inductor $L_{3}$ is needed to diminish the ripple present in the output current waveform. As shown in Fig. 3, $t 1$ and $t 2$ represent the conducting time for the power switches $S_{1}$ and $S_{2}$ respectively. Fig. 3 represents analytical voltage and current waveforms of the designed converter taking $t 1>t 2$. Starting from the top, the analytical waveform of power switches, voltage across the switches $\left(V_{S 1}\right.$ and $\left.V_{S 2}\right)$, current in the inductors $\left(I_{L 1}\right.$ and $\left.I_{L 2}\right)$, voltage across the capacitors $\left(V_{C_{1}}\right.$ and $\left.V_{C_{2}}\right)$ and current output across the inductor $\left(I_{L_{3}}\right)$ are determined.

\section{Steady state analysis of the system}

Correlation between input voltage and output voltage can be derived from the steady state volt-second balance investigation of the inductors. For the voltage and current waveforms represented in Fig. 3, the corresponding operational circuit of the projected converter through one switching sequence will follows the order of modes I, II, and IV.

Using the volt-second balance theorem on the inductors $L_{1}, L_{2} \& L_{3}$ the below equations can be achieved:

For $L_{1}$ : by applying the volt-second balance theorem,

$$
\begin{gathered}
\left(V_{1} \times t_{2}\right)+V_{1}\left(t_{1}-t_{2}\right)+\left(V_{1}-V_{C_{1}}\right)\left(1-t_{1}\right)=0, \\
V_{C_{1}}=\frac{1}{\left(1-t_{1}\right)} \times V_{1} .
\end{gathered}
$$

For $L_{2}$ :

$$
\begin{gathered}
\left(V_{2} \times t_{2}\right)+\left(V_{2}-V_{C_{2}}\right)\left(t_{1}-t_{2}\right)+\left(V_{2}-V_{C_{2}}\right)\left(1-t_{2}\right)=0, \\
V_{C_{2}}=\frac{1}{\left(1-t_{2}\right)} V_{2} .
\end{gathered}
$$


For $L_{3}$ :

$$
\begin{gathered}
\left(V_{C_{1}}+V_{C_{2}}+V_{0}\right) \times t_{2}+\left(V_{C_{1}}-V_{0}\right)\left(t_{1}-t_{2}\right)-V_{0}\left(1-t_{1}\right)=0, \\
V_{0}=\left(V_{C_{1}} \times t_{1}\right)+\left(V_{C_{2}} \times t_{2}\right), \\
V_{0}=\frac{t_{1}}{\left(1-t_{2}\right)} V_{1}+\frac{t_{2}}{\left(1-t_{2}\right)} V_{2} .
\end{gathered}
$$

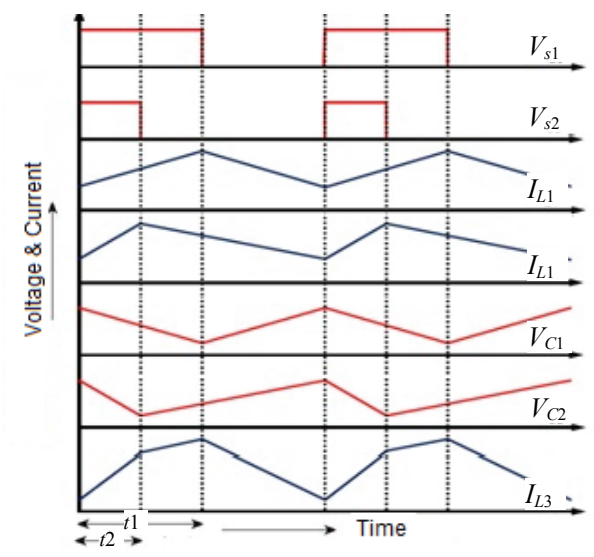

Fig. 3. Voltage and current waveforms of the designed converter vs time

\section{Multivariable control strategy for distributed hybrid power system}

Usually, in a distributed power system, to control the voltage of different buses, the controller regulates the time duration of power switches which exist in power electronics devices. In this paper, to design the controller, multivariable control strategy as an efficient method is selected [10], [11]. The basic idea of this method is to shape a family of open-loop transfer function matrixes of power system by minimizing the summation of the squared second norm of the errors between the open-loop transfer function matrixes of the system, obtained at several operating points of interest, and a desired open-loop transfer function matrix [12]. The step by step method of controller designing is explained as below:

\subsection{Determination of an open-loop transfer function of a power system}

In this step, based on the power system characteristics, the open loop transfer function of the power system is determined. The open loop transfer function of this system is defined as Eq. 8.

$$
\left[\begin{array}{l}
V_{01}(j w) \\
V_{02}(j w) \\
V_{03}(j w)
\end{array}\right]=\left[\begin{array}{ll}
G_{i, 11(j w)} & G_{i, 12(j w)} \\
G_{i, 21(j w)} & G_{i, 22(j w)} \\
G_{i, 31(j w)} & G_{i, 32(j w)}
\end{array}\right]\left[\begin{array}{l}
d_{1}(j w) \\
d_{2}(j w)
\end{array}\right] .
$$


In this equation, $V_{01}, V_{02}$ and $V_{03}$ are the voltages of PQ buses and $D_{1}, D_{2}$ are the time durations of converter switches. In addition, matrix $\boldsymbol{G}_{\boldsymbol{i}(j w)}$ is the transfer function matrix of the power system. The elements of this matrix are determined by measuring the frequency response of the power system within the frequency range of interest.

At the next step, the elements of the transfer function matrix are calculated at several operating points. The chosen operating points are the closest points to the most probable operational conditions of the distributed power system. The family of transfer function matrixes is formed as:

$$
\phi=\left\{G_{i}(j w), i=1 \text { to } 2, \omega \varepsilon \mathrm{R}\right\} .
$$

\subsection{Determination of the controller class}

In this section, the class of controller is determined. The main objective of this survey is to design a linearly parameterized multivariable controller. So, the class of the controller should be determined in the $Z$-domain. The parametric model of such a multivariable controller in the $Z$-domain is given by Eq. 10 .

$$
K(Z)=\left[\begin{array}{l}
K_{11}(Z) K_{12}(Z) K_{13}(Z) \\
K_{21}(Z) K_{22}(Z) K_{23}(Z)
\end{array}\right]
$$

The elements of the controller matrix have the same form which is stated by Eq. 11. The definition of the equation parameters is presented in Eq. 12.

$$
\begin{gathered}
K_{i j}(z, \rho)=\rho_{i j}^{T} \phi(z), \\
\left\{\begin{array}{l}
\rho_{i j}^{T}=\left[\rho_{i j, 0}, \rho_{i j, 1}, \rho_{i j, 2}, \ldots, \rho_{i j, n}\right] \\
\phi^{T}(Z)=\left[\frac{1}{1-Z^{-1}}, \frac{Z^{-1}}{1-Z^{-1}}, \frac{Z^{-2}}{1-Z^{-1}}, \ldots, \frac{Z^{-n}}{1-Z^{-1}}\right]
\end{array}\right] .
\end{gathered}
$$

In the above equations, the variable $\mathrm{n}$ is the number of zeros for each element. To calculate this parameter, the initial value of 2 is considered. Then this parameter is increased until the controller achieves appropriate dynamic performance. In this survey, the minimum value to satisfy the goals of accuracy and fast dynamic performance is $n=4$. Based on this selection, the element forms of matrix $\boldsymbol{K}(\boldsymbol{z})$ are stated as:

$$
K_{i j}(z)=\frac{\rho_{i j, 0}+\rho_{i j, 1} \cdot z^{-1}+\rho_{i j, 2} \cdot z^{-2}+\rho_{i j, 3} \cdot z^{-3}+\rho_{i j, 4} \cdot z^{-4}}{1-z^{-1}} .
$$

For more clarification, the block diagram of the controller to determine the conduction time of the switch $\left(S_{1}\right)$ is presented in Fig. 4. As the figure shows, based on the difference between the actual value of buses voltage and their reference values, the elements of the first row of the matrix $\boldsymbol{K}(\boldsymbol{z})$ determine the conduction time of converter switches. The elements of other rows of this matrix, determine the conduction time of switches $S_{2}, S_{3}$ and $S_{4}$, respectively. 


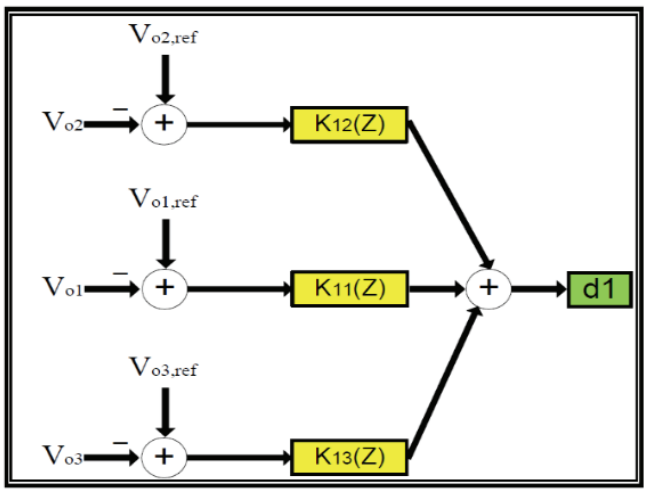

Fig. 4. Controller block diagram for determining $D_{1}$

After calculating the elements of the transfer function of $\boldsymbol{K}(\boldsymbol{z})$, based on Eq. 14, the elements of the open-loop transfer function matrix of the overall power system are obtained.

$$
L(j w)=G(j w) \times K(j w) .
$$

So, based on Eq. 15, the family of open-loop transfer function matrixes can be calculated.

$$
\Lambda=\left\{L_{i}(j w), i=1,2 \text { and } \omega \varepsilon R\right\} .
$$

\subsection{Loop Shaping by Optimization Process}

At the next step, the loop shaping of the open-loop transfer function matrixes family is done via minimizing the summation of the squared second norm of the errors between $L_{i}$ and $L_{d}$. The matrix $L_{i}$ is the open-loop transfer function matrix of the overall power system, and matrix $L_{d}$ is the desired matrix that the user expected from the power system. So, for the controller design, the procedure solves the optimization problem which is stated in Eq. 16 .

$$
\min \sum_{i=1}^{4}\left\|L_{i}-L_{d}\right\|^{2} .
$$

The elements of $L_{d}$ are determined based on the controller objectives. The diagonal elements of the matrix $L_{d}$ are considered to regulate the voltages of PQ buses with appropriate dynamic performance. In other words, by adjusting $\omega_{c}$ an appropriate dynamic response is achieved. In this paper, to provide a reasonable bandwidth and guarantee stability, $\omega_{c}=8 \times 10^{4} \mathrm{r} / \mathrm{s}$.

$$
L_{D}(S)=\left[\begin{array}{ccc}
L_{D_{1}}(S) & 0 & 0 \\
0 & L_{D_{2}}(S) & 0 \\
0 & 0 & L_{D_{3}}(S)
\end{array}\right]=\left[\begin{array}{ccc}
\frac{\omega_{c}}{S} & 0 & 0 \\
0 & \frac{\omega_{c}}{S} & 0 \\
0 & 0 & \frac{\omega_{c}}{S}
\end{array}\right] .
$$


The closed-loop sensitivity function of diagonal elements is:

$$
\begin{gathered}
S_{i}=\frac{1}{1+L_{i, q}}, \\
\left|W_{i}(j w)\left[1+L_{D, q q}(j w, \rho)\right]\right|<\operatorname{Re}\left\{\left[1+L_{D, q q}(-j w)\right]\left[1+L_{i, q q}(j w, \rho)\right]\right\}, \\
\forall \omega \in R \text { for } i=1,2 \text { and } q, p=1,2,3,
\end{gathered}
$$

where, $W_{i}(j w)$ is the weighting filter. In this survey, $W_{1}=0.6$ to guarantee the phase margin of greater than $29^{\circ}$. In addition to guarantee the stability of the power system. The parameterized controller can satisfy the stability of the power system if:

$$
\begin{aligned}
& r_{i, p q}(j w, \rho)<\frac{\operatorname{Re}\left\{\left[1+L_{D, q}(-j w)\right]\left[1+L_{i, q}(j w, \rho)\right]\right\}}{\left|W_{1}(j w)\left[1+L_{D, q q}(j w, \rho)\right]\right|}, \\
& \forall \omega \varepsilon R \text { for } i=1,2 \text { and } q, p=1,2,3,
\end{aligned}
$$

where, parameters of $r_{i, p q}$ are the off-diagonal elements of matrix $L_{i}$.

\section{Dynamic performance analysis of designed controller at different situations}

In this section, the dynamic performance and stability of proposed control strategy have been studied in different conditions. In order to have a comprehensive evaluation of the controller performance, several examinations including all the normal and critical conditions that a power system may experiences are tested. It must be mentioned that at these tests, the initial values of quantitative parameters that have been selected for a distributed power system are similar to the ones that are mentioned in the previous section. In addition, as the $\mathrm{B}_{2}$ bus is connected to all of the PQ buses as shown in Fig. 5, then it is not necessary to measure the voltage of each PQ bus and the voltage of the $\mathrm{B}_{2}$ bus is a comprehensive representative of the overall power system voltage $[13,14]$. It is necessary to mention that in following tests, the RMS value of the $B_{2}$ bus voltages is measured. The reference value of this parameter at a normal condition is $V=20 \mathrm{kV}$. These tests are described as below:

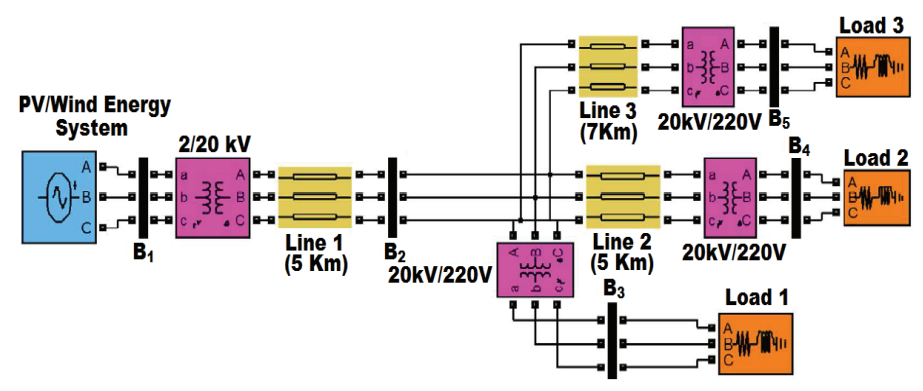

Fig. 5. Simulated distributed hybrid PV/wind power system in MATLAB/SIMULINK 


\subsection{Changing the power demand at $P Q$ bus}

In this examination, the ability of a controller to respond to different power demands at PQ buses has been analyzed. This test is divided into two parts. In the first section, the variation of active power and at the second part, reactive power alternation has been studied.

For this reason, at the first evaluation, at $t=4 \mathrm{~s}$, the power demand of three PQ buses has been increased from 1.1 MW to 1.7 MW. For the second scenario, like in the previous test, the reactive power demand has been changed and at $t=4 \mathrm{~s}$, the amount of reactive power that was consumed at three PQ buses is increased from 350 kvar to 550 kvar as shown in Fig. 6.
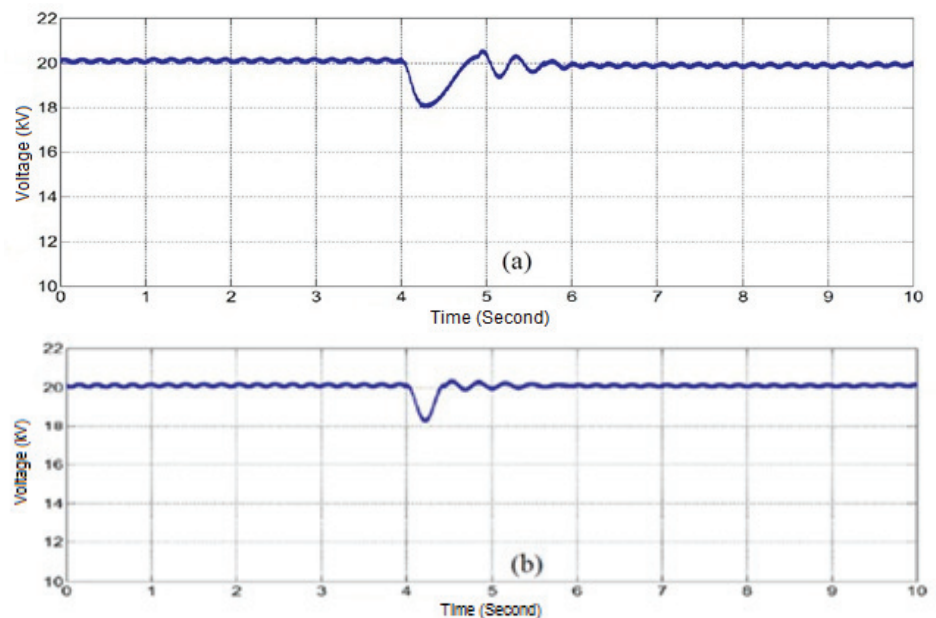

Fig. 6. The voltage of $\mathrm{B}_{2}$ bus in Test $\mathrm{A}$, during a) increase of demanded active power, $\mathrm{b}$ ) increase of demanded Reactive power

At the first examination, normal conditions are considered for the power system. The quantitative characteristics of the power system are: $\lambda=1, T=320 \mathrm{~K}$, Wind Speed $(v w)=8 \mathrm{~m} / \mathrm{s}$, the reference value of the $\mathrm{B}_{2}$ bus voltage $=20 \mathrm{kV}$.

\subsection{Variations of ambient conditions at renewable energy sources}

In this part, two of the prevalent incidents that affect the performance of distributed renewable power systems are studied. These incidents are caused by the reduction of sun irradiation $(\lambda=1$ to $\lambda=0.2)$ and continuous variation of wind speed $(v w=10 \mathrm{~m} / \mathrm{s}$ to $v w=1 \mathrm{~m} / \mathrm{s})$. The voltage of the $B_{2}$ bus is measured and is presented in Fig. 7 .

\subsection{Variations of the reference voltage value}

In this test, by changing the quantity of reference voltage, the flexibility of a power system in changing bus voltage has been tested. The reference voltage $V=20 \mathrm{kV}$ is increased to $V=25 \mathrm{kV}$ at $t=4 \mathrm{~s}$ and then is decreased to $V=17 \mathrm{kV}$ at $t=6 \mathrm{~s}$. The voltage of the $\mathrm{B}_{2}$ bus is measured and shown in Fig. 8. 

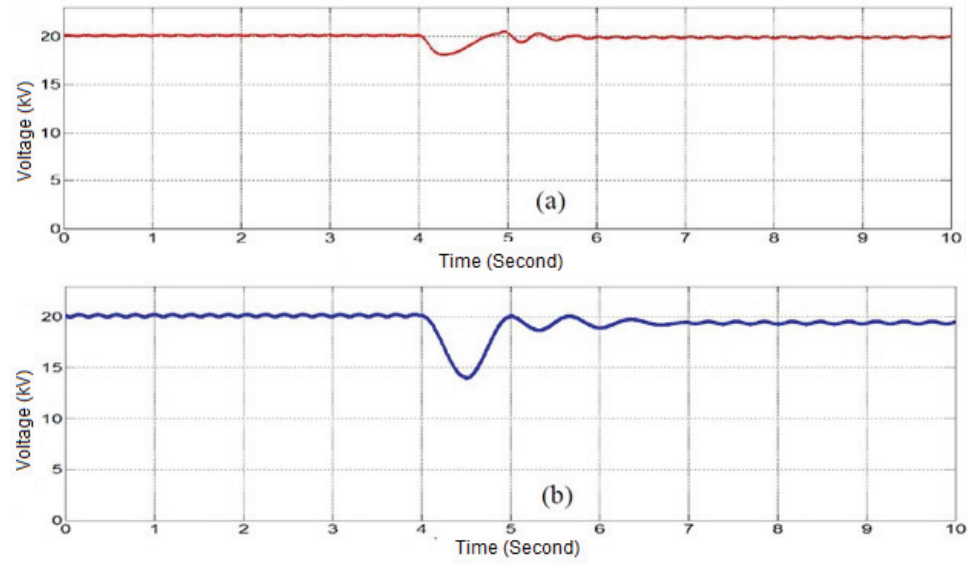

Fig. 7. The voltage of $B_{2}$ bus in Test $B$, during a) decrease of sun irradiation, b) decrease of wind speed

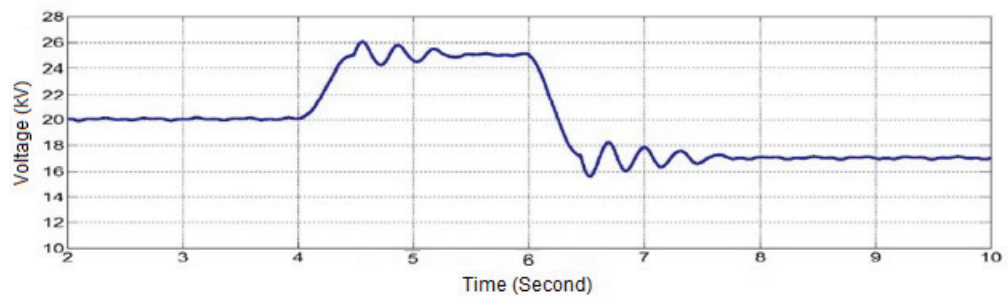

Fig. 8. The voltage of $B_{2}$ bus in Test $C$

\subsection{Occurrence of fault condition in one of the $P Q$ buses}

In this test, by inserting the symmetrical fault condition to one of the PQ buses $\left(\mathrm{B}_{3}\right)$ and observing the voltage of other PQ buses, the independence of PQ buses voltage has been analyzed and shown in Fig. 9(a).
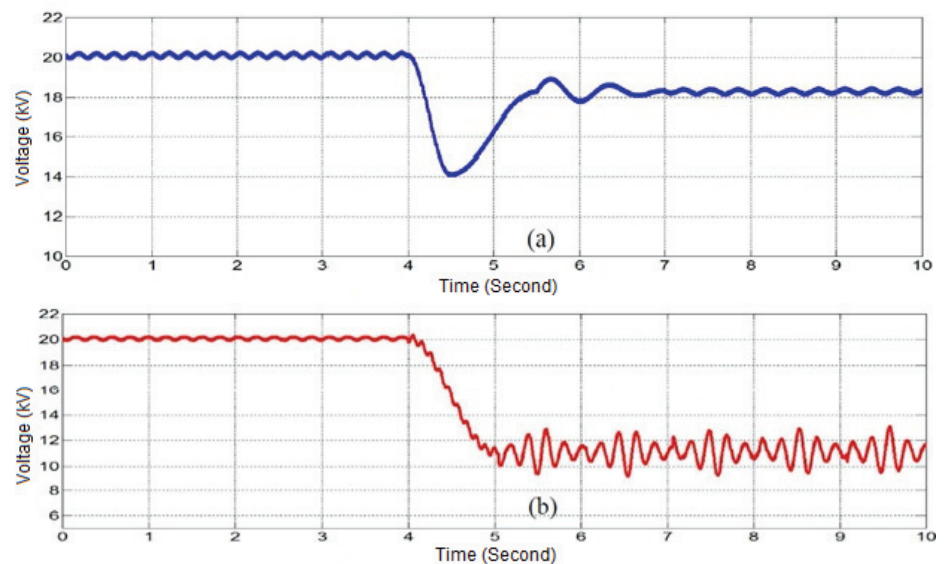

Fig. 9. The voltage of $B_{2}$ bus in Test $D$ with a) multivariable controller, b) conventional controller 
As the figure shows, occurrence of electrical fault at $t=4 \mathrm{sec}$ at one of the buses has negligible influences on the other parts of the power system. For instance, this test has been repeated with a conventional controller (PID controller) and the voltage of the $\mathrm{B}_{2}$ bus has been measured again and is shown in Fig. 9(b).

As this figure shows, the PID controller cannot maintain the stability of the voltage of the distributed power system. By comparing the results of these two controllers, the efficiency of a multivariable controller is revealed.

\subsection{The changing structure of a hybrid power supply distribution system}

In this test, the response of a multivariable controller to the power system structure changes is evaluated. To analyze this feature, at $t=5 \mathrm{~s}$, the power line that connects the $\mathrm{B}_{5}$ bus to $\mathrm{B}_{2}$ bus is cut off. As Fig. 10 shows, inserted perturbation doesn't make the voltage of the power system unstable and after about 0.5 second, the controller regulates the voltage of a common bus of $\mathrm{B}_{2}$ at predetermined value again. In addition, during transient time, the increase of voltage at the proposed bus is insignificant.

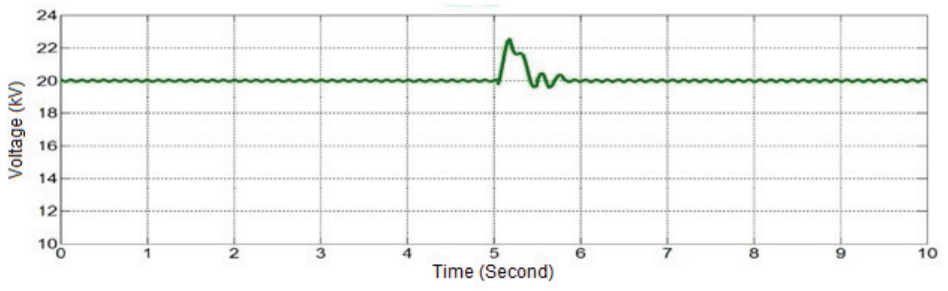

Fig. 10. The voltage of $\mathrm{B}_{2}$ bus in Test $\mathrm{E}$

\section{Conclusions}

This paper proposes two important subjects. In the first part, a novel double-input DC-DC converter that can be applied in a distributed power system is introduced. The theoretical principles of the proposed converter are presented, and based on these principles; the current of converter's inductors, the voltage of converter's capacitors and the output voltage are discussed. In the second section, by applying a designed converter, a distributed hybrid PV/wind power system is simulated. To control the power switches of power system's converters, a multivariable controller is designed. This controller has some exclusive features that are: 1) regulating the voltage of a power system in normal and critical conditions, 2) isolating the voltage of different buses from each other, 3) changing the reference value of power system voltage with appropriate dynamic performance. The simulation and experimental results confirm satisfactory performance of the proposed multivariable controller in regulation of the distributed hybrid power system voltage at different conditions. The proposed methodology is general and applicable to different distributed renewable power systems with any number of energy sources and PQ buses. 


\section{Acknowledgements}

Authors are thankful to the IIT(ISM), Dhanbad and UNIVERSITY GRANTS COMMISSION, Bahadurshah Zafar Marg, New Delhi, India for granting financial support under Major Research Project entitled "Development of Hybrid Off-grid Power Supply System for Remote Areas [UGC Project: F. No. 42 152/2013(SR), w.e.f. 01/04/2013]" and also grateful to the Under Secretary and Joint Secretary of UGC, India for their active co-operation. Authors are also thankful to the National Institute of Solar Energy, Gurgaon-Faridabad Road, Gwalpahari, Gurgaon, Haryana, India for allowing the opportunity to work at their campus and for their active co-operation.

\section{References}

[1] Luque A., Hegedus S., Handbook of Photovoltaic Science and Engineering, Wiley (2003).

[2] Dali M., Belhadj J., Roboam X., Hybrid solar-wind system with battery storage operating in gridconnected and standalone mode: Control and energy management-Experimental investigation, 7th International Conference on Sustainable Energy Technologies, pp. 2587-2595 (2010).

[3] Bogaraj T., Kanakaraj J., Kumar K.M., Optimal sizing and cost analysis of hybrid power system for a stand-alone application in Coimbatore region: a case study, Archives of Electrical Engineering, vol. 64, no. 1, pp. 139-155 (2015).

[4] Ciampichetti S., Corradini M.L., Ippoliti G., Orlando G., Sliding Mode Control of Permanent Magnet Synchronous Generators for Wind Turbines, IEEE Conference on IECON $-37^{\text {th }}$ Annual Conference on IEEE Industrial Electronics Society, Poland, pp. 740-745 (2011).

[5] Izadbakhsh M., Rezbani A., Gandomkar M., Dynamic response improvement of hybrid system by implementing ANN-GA for fast variation of photovoltaic irradiation and FLC for wind turbine, Archives of Electrical Engineering, vol. 64, no. 2, pp. 291-314 (2015).

[6] Izadbakhsh M., Rezvani A., Gandomkar M., Improvement of microgrid dynamic performance under fault circumstances using ANFIS for fast varying solar radiation and fuzzy logic controller for wind system, Archives of Electrical Engineering, vol. 63, no. 4, pp. 551-578 (2014).

[7] Nejabatkhah F., Danyali S., Hosseini S.H., Sabahi M., Niapour S.M., Modeling and Control of a New Three-Input DC-DC Boost Converter for Hybrid PV/FC/Battery Power System, IEEE Transactions on Power Electronics, vol. 27, no. 5, pp. 2309-2324 (2012).

[8] Pandiarajan K., Babulal C.K., Fuzzy ranking based non-dominated sorting genetic algorithm-II for network overload alleviation, Archives of Electrical Engineering, vol. 63, no. 3, pp. 367-384 (2014).

[9] Mangaiyarkarasi S.P., Sree Renga Raja T., PSO based optimal location and sizing of SVC for novel multi objective voltage stability analysis during $N-2$ line contingency, Archives of Electrical Engineering, vol. 63, no. 4, pp. 535-550 (2014).

[10] Qi W., Liu J., Chen X., Christofides P.D., Supervisory predictive control of standalone wind/solar energy generation systems, IEEE Transactions on Control Systems Technology, vol. 19, no. 1, pp. 199-207 (2011).

[11] Uzunoglu M., Onar O.C., Alam M.S., Modeling, control and simulation of a PV/FC/UC based hybrid power generation system for stand-alone applications, Renewable Energy, vol. 34, no. 3, pp. 509-520 (2009).

[12] Dash P.K., Padhee M., Barik S.K., Estimation of Power Quality Indices in Distributed Generation Systems during Power Islanding Conditions, International Journal of Electrical Power \& Energy Systems, vol. 36, no. 1, pp. 18-30 (2012).

[13] Xiao W., Edwin F.F., Spagnuolo G., Jatskevich J., Efficient Approaches for Modeling and Simulating Photovoltaic Power Systems, IEEE Journal on Photovoltaics, vol. 3, no. 1, pp. 500-508 (2013).

[14] Said S., Massoud A., Benammar M., Ahmed S., Guy C., Gerard R., A Matlab/Simulink Based Photovoltaic Array Model Employing Sim Power Systems Toolbox, Journal of Energy and Power Engineering, vol. 6, no. 12, pp. 1965-1975 (2012). 